\title{
Studies on Conductive Silicone Rubber Compounds
}

\author{
K. G. PRINCY, ${ }^{1}$ RANI JOSEPH, ${ }^{1}$ C. SUDHA KARTHA ${ }^{2}$ \\ ${ }^{1}$ Department of Polymer Science and Rubber Technology, Cochin University of Science and Technology, \\ Cochin 682 022, Kerala, India \\ ${ }^{2}$ Department of Physics, Cochin University of Science and Technology, Cochin 682 022, Kerala, India
}

Received 2 May 1997; accepted 29 December 1997

\begin{abstract}
The electrical conductivity of silicone rubber vulcanizates containing carbon blacks [e.g., acetylene black, lamp black, and ISAF (N-234) black] were investigated. The change in electrical conductivity with varying amounts of carbon blacks and the temperature dependence was measured. The mechanical properties like tensile strength, tear strength, elongation at break, hardness, etc., of the vulcanizates were determined. A comparative study of the electrical conductivity of the composites revealed that the electrical conductivity of the composites made with acetylene black was higher than that of the composites made of other blacks. (c) 1998 John Wiley \& Sons, Inc. J Appl Polym Sci 69: 1043-1050, 1998
\end{abstract}

Key words: silicone rubber; acetylene black; lamp black; ISAF black; electrical resistivity

\section{INTRODUCTION}

Electrical conductivity is important in many rubber and plastic compounds for antistatic applications, wire and cable sheathing, shielding against electromagnetic interference, etc. Elastomers and plastics are insulators to which conductivity is imparted by the addition of finely divided fillers of high intrinsic conductivity, such as carbon black. ${ }^{1,2}$ The structures of carbon blacks and the influence of the structure on the properties of filled rubbers are well established. ${ }^{1,3,4}$

Conductive silicone rubber has received considerable attention, probably because of its stable current time characteristics, controlled thermal coefficient of resistivity, high thermal limits, and capability of being fabricated by conventional techniques. Numerous research papers ${ }^{5-10}$ and review articles ${ }^{11}$ have been published on conductive polymers.

\footnotetext{
Correspondence to: R. Joseph.
}

Journal of Applied Polymer Science, Vol. 69, 1043-1050 (1998)

(1) 1998 John Wiley \& Sons, Inc. CCC 0021-8995/98/051043-08
This article reports the effect of different types of carbon blacks [e.g., acetylene black, lamp black, and ISAF (N-234) black], copper powder, and graphite on electrical conductivity and mechanical properties of silicone rubber compounds.

\section{EXPERIMENTAL}

\section{Materials Used}

1. Silicone rubber (general purpose silicone rubber), supplied by GE Silicones having 40 shore A hardness.

2. Acetylene black, with average EM particle diameter, $41 \mathrm{~nm}$ and dibutyl phthalate (DBP) absorption, $310 \mathrm{~mL} 100 \mathrm{~g}^{-1}$, supplied by Travancore Electrochemicals (Kerala, India).

3. High structure ISAF (N-234) black, with an average particle diameter, $23 \mathrm{~nm}, \mathrm{DBP}$ absorption, $125 \mathrm{~mL} 100 \mathrm{~g}^{-1}$, supplied by Cabot India Ltd. (Bombay, India).

4. Lamp black, with an average particle diameter, $100 \mathrm{~nm}$ supplied by Cabot India Ltd. 
Table I Formulation of Compounds

\begin{tabular}{lcccccccc}
\hline Mix & SR & DCP & AB & LB & ISAF & Cu & G & $\begin{array}{c}\text { Cure Time at } 180^{\circ} \mathrm{C} \\
\text { (in min) }\end{array}$ \\
\hline$A_{1}$ & 100 & 2.5 & $5(2.7)$ & - & - & - & - & 1.52 \\
$A_{2}$ & 100 & 2.5 & $10(5.5)$ & - & - & - & - & 1.25 \\
$A_{3}$ & 100 & 2.5 & $20(11)$ & - & - & - & - & 1.19 \\
$A_{4}$ & 100 & 2.5 & $30(16.6)$ & - & - & - & - & 1.17 \\
$A_{5}$ & 100 & 2.5 & $40(22.1)$ & - & - & - & - & 1.15 \\
$A_{6}$ & 100 & 2.5 & $45(24.9)$ & - & - & - & - & 1.14 \\
$B_{1}$ & 100 & 2.5 & - & $10(2.6)$ & - & - & - & 1.12 \\
$B_{2}$ & 100 & 2.5 & - & $20(5.2)$ & - & - & - & 1.28 \\
$B_{3}$ & 100 & 2.5 & - & $30(7.8)$ & - & - & - & 1.36 \\
$B_{4}$ & 100 & 2.5 & - & $40(10.3)$ & - & - & - & 1.48 \\
$B_{5}$ & 100 & 2.5 & - & $50(12.9)$ & - & - & - & 1.64 \\
$B_{6}$ & 100 & 2.5 & - & $60(15.5)$ & - & - & - & 1.78 \\
$C_{1}$ & 100 & 2.5 & - & - & $10(5.8)$ & - & - & 1.48 \\
$C_{2}$ & 100 & 2.5 & - & - & $20(11.7)$ & - & - & 1.88 \\
$C_{3}$ & 100 & 2.5 & - & - & $30(17.5)$ & - & - & 2.34 \\
$C_{4}$ & 100 & 2.5 & - & - & $40(23.4)$ & - & - & 1.04 \\
$D_{1}$ & 100 & 2.5 & $10(5.5)$ & - & - & $25(3.1)$ & $10(4.7)$ & 0.94 \\
$D_{2}$ & 100 & 2.5 & $20(11)$ & - & - & $25(3.1)$ & $10(4.7)$ & 0.92 \\
$D_{3}$ & 100 & 2.5 & $30(16.6)$ & - & - & $25(3.1)$ & $10(4.7)$ & 0.91 \\
$D_{4}$ & 100 & 2.5 & - & - & - & $25(3.1)$ & $10(4.7)$ & 0.88 \\
$E$ & 100 & 2.5 & - & - & - & - & - & 0.90 \\
$F$ & 100 & 2.5 & - & - & - & $75(9.3)$ & - & 0.71 \\
$G$ & 100 & 2.5 & - & - & - & - & $40(18.8)$ & \\
\hline
\end{tabular}

All values are expressed as parts per hundred rubber ( $\mathrm{phr}$ ) by weight. SR, silicone rubber; Cu, copper powder; DCP, dicumyl peroxide; G, graphite; AB, acetylene black; LB, lamp black; ISAF, intermediate super abrasion furnace black; volume \% loading of the fillers are given in parentheses.

5. Graphite powder, supplied by Asian Minerals (Madras, India).

6. Electrolytic purpose grade copper powder supplied by Merck (India).

7. $40 \%$ active dicumyl peroxide-Dicumyl peroxide used was a crystal with a purity of $99 \%$ and a density of $1.02\left(\mathrm{gm} \mathrm{cm}^{-3}\right)$. The recommended processing temperature of the material is $160-200^{\circ} \mathrm{C}$.

\section{Sample Preparation}

The compounds as per the formulation given in Table I were mixed in a Brabender Plasticorder PL3S with a rotor speed of $50 \mathrm{rpm}$ at room temperature for $6 \mathrm{~min}$. Each batch was then sheeted out by passing through a two roll mill of size $(15 \times 33$ $\mathrm{cm})$, which was convenient for the subsequent preparation of test specimens. The compounds were kept for $24 \mathrm{~h}$ for maturation. The optimum cure time (time for attaining $90 \%$ of the maximum torque) of each sample was determined at $180^{\circ} \mathrm{C}$ using Goettfert Elastograph model 67.85 and are listed in Table I.
The compounds were compression-molded at $180^{\circ} \mathrm{C}$, in an electrically heated hydraulic press, into 1-mm-thick sheets. For this, the mold was preheated to $180^{\circ} \mathrm{C}$, a piece of preformed material was placed directly in the mold cavity, and compressed under an hydraulic clamp pressure of 200 $\mathrm{psi} / \mathrm{kg} \mathrm{cm}^{-2}$. Upon completion of the required cure cycle, the pressure was released and the sheet was stripped from the mold and suddenly cooled by plunging into cold water. After a few seconds, the samples were taken from the cold water.

Dumbbell-shaped test specimens were punched out of these compression-molded sheets along the mill grain direction. The tensile properties were measured on a Zwick UTM model 1445 using a crosshead speed of $500 \mathrm{~mm} \mathrm{~min}{ }^{-1}$ according to ASTM D 412. Data presented are average values after testing more than three samples.

Angular test specimens were punched out of the sheets. Tear resistance of the vulcanizates were measured on the Zwick UTM according to ASTM D 264.

The hardness (shore A) of each sample was 
also noted, according to ASTM D 2240. Resistivity of each sample was determined using the twoprobe method. Data presented are the average of two samples. The samples with typical dimensions of $3 \times 1.5 \times 0.1 \mathrm{~cm}^{3}$ were prepared for direct current electrical resistivity measurements. The sample was inserted between two electrodes. The contact resistance between the electrode and the sample was minimized using silver paint. A potential of $6 \mathrm{~V}$ was applied, and the resulting current through the circuits was noted at a rotary vacuum of $10^{-2}$ torr. For high resistivity samples, the resulting current through the circuit was measured using an electrometer amplifier (model no. EA 815). For low resistivity samples, the resulting current was measured using a digital multimeter (APLAB model 1087). Resistance of the samples was calculated using the equation, $R$ $=V / I$, where $V$ is applied voltage and $I$ is resulting current. The resistivity in each case was calculated using the equation, $\rho=(R A / t)$, where $A$ is the area of the sample and $t$ is the thickness of the sample. The temperature dependence of resistivity was measured in the temperature range of 25 to $150^{\circ} \mathrm{C}$ by raising the temperature at a heating rate of $2^{\circ} \mathrm{C} \mathrm{min}{ }^{-1}$ and then by slow cooling up to $50^{\circ} \mathrm{C}$. The cooling rate also was controlled by adjusting the voltage given to the heating coil. The cooling rate was $1.5^{\circ} \mathrm{C} \min ^{-1}$ up to $75^{\circ} \mathrm{C}$ and then it was $1^{\circ} \mathrm{C} \min ^{-1}$ up to $50^{\circ} \mathrm{C}$. To test the reproducibility of the experimental results, the temperature cycling was repeated for the same test piece.

\section{RESULTS AND DISCUSSION}

Table II summarizes the physical properties of the vulcanizates. It is apparent that, with increasing the amount of different blacks, both conductivity and hardness of the composites increased. However, tensile strength, tear strength, and elongation at break gradually decreased.

The cure times of compounds $A_{1}-A_{5}$ decreases as the concentration of acetylene black increases. The decrease in cure time may be due to the accelerating effect of acetylene black on vulcanization. For compounds $B_{1}-B_{6}$, the cure time increases gradually as the concentration of lamp black increases. This may be due to the retarding effect of lamp black. For compounds $C_{1}-C_{4}$ also, the cure time increases with an increase in the con-

Table II Properties of the Mixes

\begin{tabular}{|c|c|c|c|c|c|c|}
\hline $\begin{array}{l}\text { Mix } \\
\text { No. }\end{array}$ & $\begin{array}{l}\text { Tensile } \\
\text { Strength } \\
\left(\mathrm{N} \mathrm{mm}^{-2}\right)\end{array}$ & $\begin{array}{c}\text { Tensile Modulus } \\
\text { at } 100 \% \text { Elongation } \\
\left(\mathrm{N} \mathrm{mm}^{-2}\right)\end{array}$ & 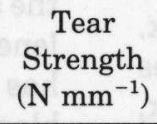 & $\begin{array}{c}\text { Elongation } \\
\text { at Break } \\
(\%)\end{array}$ & $\begin{array}{l}\text { Hardness } \\
\text { (Shore A) }\end{array}$ & $\begin{array}{l}\text { Volume } \\
\text { Resistivity } \\
(\Omega \mathrm{cm})\end{array}$ \\
\hline$A_{1}$ & 7.32 & 2.20 & 24.73 & 299.45 & 30 & $8.343 \times 10^{11}$ \\
\hline$A_{2}$ & 6.86 & 2.82 & 22.33 & 352.87 & 35 & $1.263 \times 10^{5}$ \\
\hline$A_{3}$ & 5.18 & 3.22 & 17.84 & 211.42 & 45 & $1.342 \times 10^{2}$ \\
\hline$A_{4}$ & 3.27 & 3.31 & 14.37 & 99.68 & 55 & 24.648 \\
\hline$A_{5}$ & 3.02 & - & 11.54 & 64.66 & 70 & 10.648 \\
\hline$B_{1}$ & 5.53 & 1.19 & 17.33 & 416.81 & 25 & $1.116 \times 10^{13}$ \\
\hline$B_{2}$ & 5.19 & 1.89 & 17.34 & 355.50 & 35 & $3.143 \times 10^{8}$ \\
\hline$B_{3}$ & 4.78 & 2.03 & 16.03 & 306.15 & 40 & $4.999 \times 10^{4}$ \\
\hline$B_{4}$ & 3.26 & 2.49 & 13.92 & 240.41 & 55 & $1.927 \times 10^{3}$ \\
\hline$B_{5}$ & 2.73 & 2.62 & 12.75 & 134.37 & 60 & $9.755 \times 10^{2}$ \\
\hline$B_{6}$ & 1.95 & - & 9.52 & 90.36 & 65 & $1.915 \times 10^{2}$ \\
\hline$C_{1}$ & 6.83 & 1.24 & 18.50 & 384.71 & 25 & $3.397 \times 10^{6}$ \\
\hline$C_{2}$ & 2.36 & 1.60 & 14.97 & 239.61 & 35 & $3.996 \times 10^{3}$ \\
\hline$C_{3}$ & 2.08 & - & 9.28 & 41.72 & 43 & $1.380 \times 10^{3}$ \\
\hline $\mathrm{C}_{4}$ & 1.93 & - & 8.41 & 35.37 & 55 & $6.364 \times 10^{2}$ \\
\hline$D_{1}$ & 5.48 & 2.19 & 24.23 & 274.75 & 35 & $3.881 \times 10^{11}$ \\
\hline$D_{2}$ & 5.39 & 3.53 & 23.82 & 174.26 & 50 & $8.024 \times 10^{2}$ \\
\hline$D_{3}$ & 4.95 & 3.74 & 23.02 & 150.00 & 59 & $1.576 \times 10^{2}$ \\
\hline$D_{4}$ & 4.66 & 4.00 & 17.01 & 137.91 & 65 & 13.482 \\
\hline$E$ & 7.44 & 1.34 & 20.87 & 407.80 & 27 & Very high \\
\hline$F$ & 4.55 & 1.64 & 14.18 & 282.72 & 55 & $1.694 \times 10^{12}$ \\
\hline$G$ & 4.30 & 1.69 & 14.96 & 334.83 & 50 & $4.53 \times 10^{11}$ \\
\hline
\end{tabular}




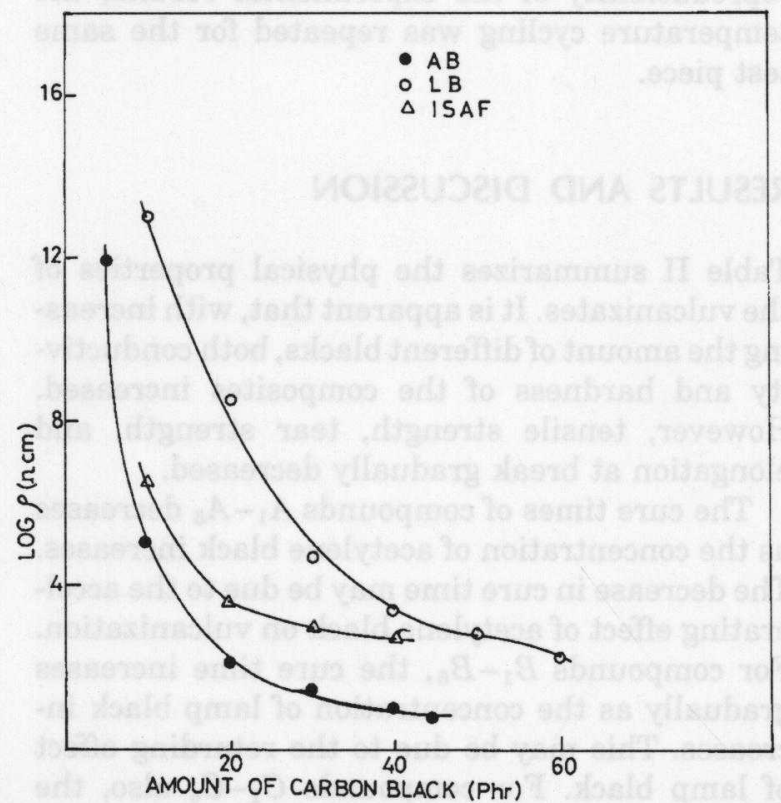

Figure 1 Log $\rho$ vs. amount of carbon black. ( ) Acetylene black (AB). (O) Lamp black (LB). ( $\triangle$ ) ISAF black.

centration of ISAF (N-234) black. This may be due to the slight retarding effect of ISAF black. For compounds $D_{1}-D_{4}$, the cure time decreases with increasing concentration of acetylene black, similar to those for compounds $A_{1}-A_{5}$.

The decrease in tensile and tear strength is due to the decreasing volume fraction of silicone rubber in the compounds containing a higher concentration of carbon blacks. As the concentration of carbon black increases, there is not enough rubber matrix to hold the particles of the carbon black; thus the tensile and tear strength decreases. Elongation at break also decreases with an increase in carbon black loading.

The compounds containing copper powder ( 25 $\mathrm{phr})$ and graphite (10 phr), along with varying amounts of acetylene black, also shows a decrease in tensile strength, tear strength, and elongation at break.

The hardness and tensile modulus at $100 \%$ elongation increases with an increase in the concentration of carbon black.

Figure 1 shows the variation in resistivity of silicone rubber compounds with the concentration of different blacks at room temperature. At low loadings of carbon black, the conductivity of the compounds were very low. This was because the carbon black particles were isolated from each other, and there was no conducting path. As the loading of carbon blacks was increased, the con- ductivity increased rapidly up to a particular concentration region; thereafter, the increase in conductivity was not so rapid. This is because, when the amount of carbon black was increased, cluster or aggregates of carbon blacks were formed and a conducting throughgoing path was formed. Thus, the internal contact resistance between the aggregates decreased as the loading level increased. Once a high enough loading was reached so that contact resistance between the aggregates was no longer significant and there was not any significant increase in conductivity with a further increase in loading. ${ }^{1}$

A comparative electrical conductivity study of the compounds revealed that the conductivity of the compounds filled with acetylene black is higher than that with ISAF black, which has conductivity higher than that with lamp black. This behavior can be explained by considering the very high structure of acetylene black. When acetylene black was added to silicone rubber aggregates of acetylene black comes in contact with each other and a conducting path was easily formed in a concentration range of $10-15 \mathrm{phr}$ by weight. Because the structure of ISAF black is not as high as acetylene black, the compounds filled with ISAF black has lower conductivity, compared with acetylene black. Because lamp black has a still lower structure, the conductivity is low even when a higher amount of lamp black was added.

Figures 2 and 3 show the temperature dependence of resistivity for 30 and $40 \mathrm{phr}$ acetylene black containing compounds, respectively. As the temperature was increased, the conductivity decreases. This behavior may be due to two factors: (1) the thermal expansion of silicone rubber is higher than that of acetylene black and so the gap width between the aggregates increases resulting in decrease in conductivity; and (2) when temperature increases, some of the aggregates of carbon black breaks down and so the gap width between the aggregates increases and so conductivity decreases. On cooling, the conductivity increases. This may be either due to the contraction of silicone rubber so that the gap width decreases or due to the reagglomeration of the particles resulting in gap width decrease and therefore conductivity increases. ${ }^{1,9,12}$

The nature of the hysteresis loop in the $\rho=f(T)$ curve during the heating-cooling cycle is shown in Figure 2 and 3. It is reported that the hysteresis loop results from the thermal mismatch between filler and polymer. ${ }^{10,12}$ The uneven thermal expan- 


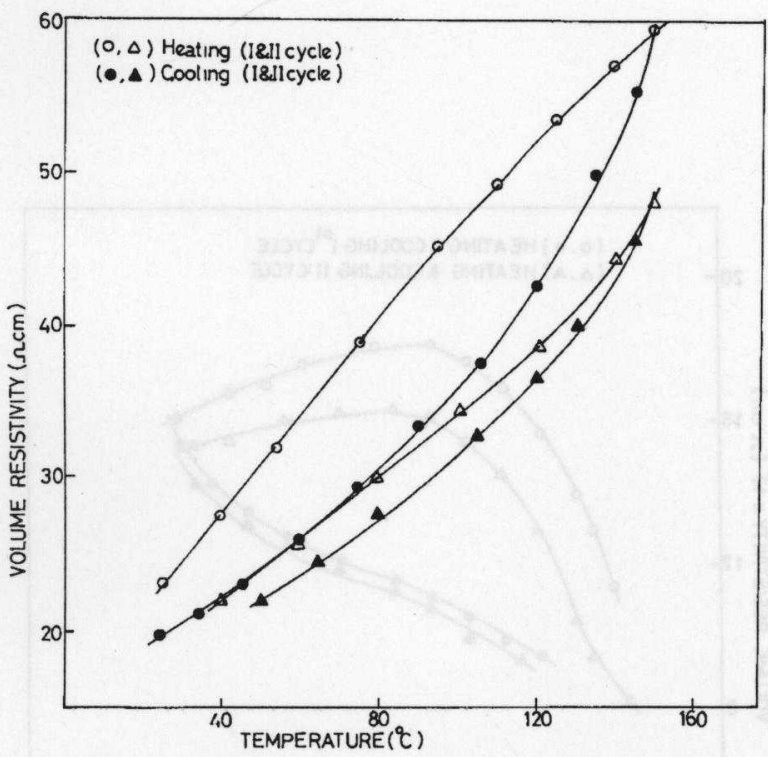

Figure 2 Resistivity $v s$. temperature for the compound containing $30 \mathrm{phr}$ of acetylene black. (O) First heating cycle. $(\bullet)$ First cooling cycle. $(\triangle)$ Second heating cycle. ( $\boldsymbol{\Delta})$ Second cooling cycle.

sion of rubber and acetylene black may be one of the reasons for the creation of a hysteresis loop.

When temperature increases, some of the aggregates of carbon black breaks down and the gap

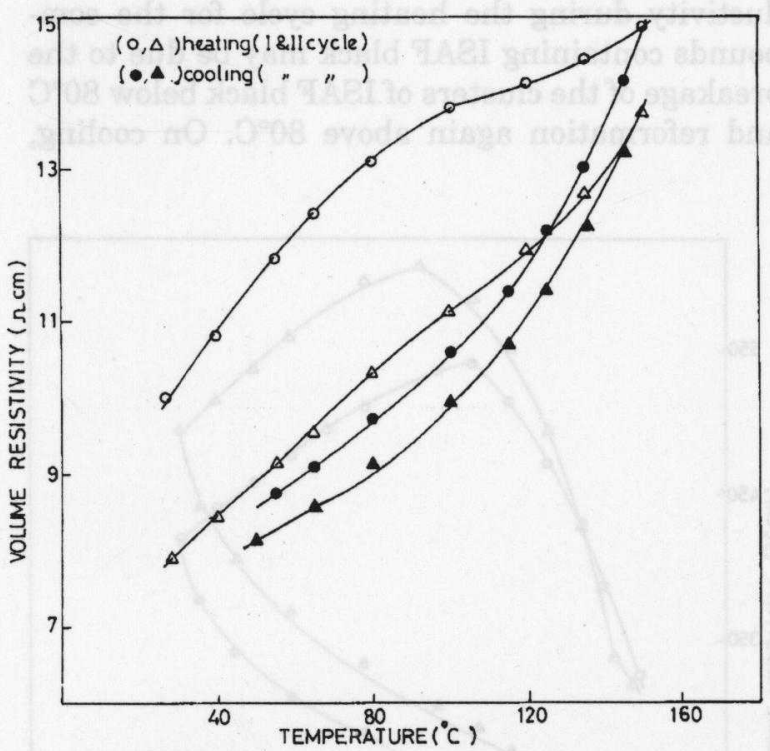

Figure 3 Resistivity vs. temperature for the compound containing $40 \mathrm{phr}$ of acetylene black. (O) First heating cycle. $(\bullet)$ First cooling cycle. $(\Delta)$ Second heating cycle. ( $\mathbf{\Delta})$ Second cooling cycle.

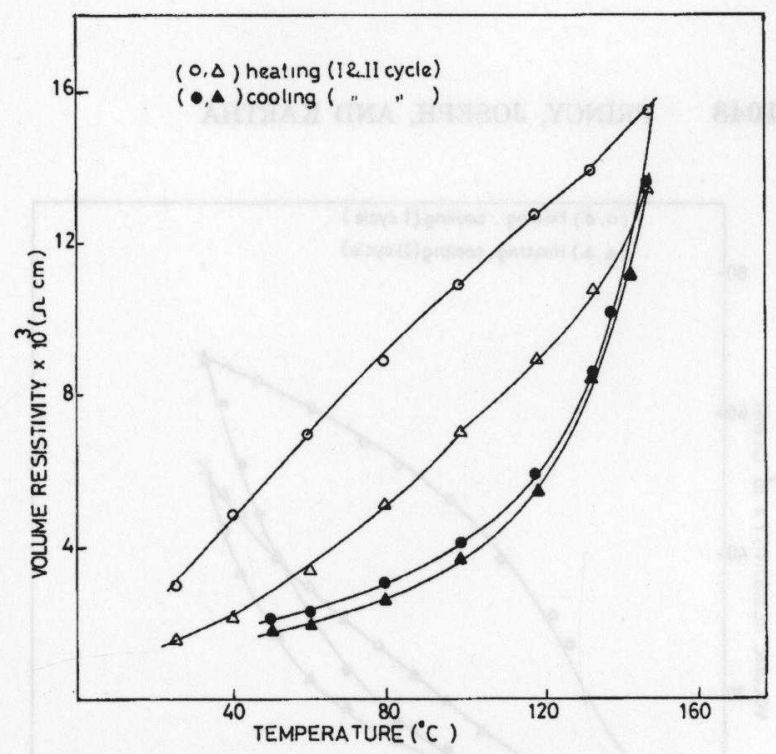

Figure 4 Resistivity vs. temperature for the compound containing $40 \mathrm{phr}$ of lamp black. (O) First heating cycle. (๑) First cooling cycle. $(\triangle)$ Second heating cycle. ( $\mathbf{\Delta}$ ) Second cooling cycle.

width between the aggregates increases and so the conductivity decreases. On cooling, reagglomeration of the particles takes place, the gap width decreases, and the conductivity increases. During cooling, the size of the aggregates of acetylene black may be greater than that at the heating time. This may be one of the reasons for the higher conductivity on cooling than on heating; thus, the hysteresis loop results. Also, it has been reported ${ }^{8}$ that the resistivity of the compounds decreases after heat aging at $150-250^{\circ} \mathrm{C}$ and the decrease in resistivity during aging was explained, due to the increase in the concentration of the carbon black in the system, as a result of a loss of mass $\left(3.8 \%\right.$ after $5500 \mathrm{~h}$ at $\left.150^{\circ} \mathrm{C}\right)$. Herein, also after the heating cycle, aging of silicone rubber takes place, and the conductivity on cooling will be higher than on heating; thus, the hysteresis loop results.

The conductivity values shown in the graph during the cooling cycle is only up to $50^{\circ} \mathrm{C}$, because the cooling rate was very low below $50^{\circ} \mathrm{C}$. If we extrapolate the curve to room temperature, the cooling cycle endpoint will be the same as the start point of the second heating cycle.

Figures 4 and 5 show the temperature dependence of resistivity for vulcanizates containing 40 and $50 \mathrm{phr}$ lamp black, respectively. On heating, the conductivity decreases, due to the thermal 


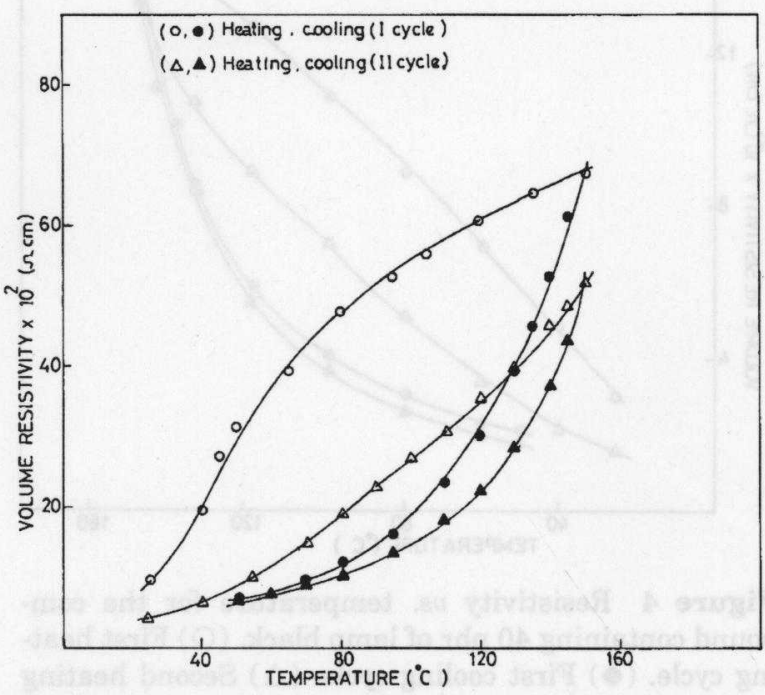

Figure 5 Resistivity vs. temperature for the compound containing $50 \mathrm{phr}$ of lamp black. (O) First heating cycle. ( ) First cooling cycle. $(\triangle)$ Second heating cycle. ( $\Delta$ ) Second cooling cycle.

expansion of the silicone rubber. This may also be due to the disintegration of lamp black aggregates. On cooling, the conductivity increases due to the contraction of silicone rubber and may also be due to the reagglomeration of lamp black particles. The overlap of the cooling cycle curves in Figure 4 may be due to the same size of the aggregates of lamp black during the cooling process. When the concentration of lamp black increases to $50 \mathrm{phr}$, overlapping of the cooling curves takes place at a temperature lower than $80^{\circ} \mathrm{C}$. This may be because the size of the aggregates may be the same only at a low temperature.

Figures 6 and 7 show the temperature dependence of resistivity for 30 and $40 \mathrm{phr}$ ISAF carbon black containing compounds, respectively. The resistivity increases on heating up to $80^{\circ} \mathrm{C}$ and then decreases. Even though it is not very clear why there is a decrease in resistivity above $80^{\circ} \mathrm{C}$, it has been repeatedly observed in several samples: an increase in resistivity up to $80^{\circ} \mathrm{C}$ and then a decrease in its value. A similar observation has been reported earlier by Abo-Hashem and colleagues ${ }^{9}$ in butyl rubber mixed with SRF carbon black. They have observed a decrease in conductivity below $60^{\circ} \mathrm{C}$ for the composites containing 40 and $70 \mathrm{phr} \mathrm{SRF}$; above $60^{\circ} \mathrm{C}$, thermally activated behavior showing an increase in conductivity during the heating cycle is noted. It was reported that the structure of SRF black suffers from slight breakage below $60^{\circ} \mathrm{C}$ and reformation above $60^{\circ} \mathrm{C}$,

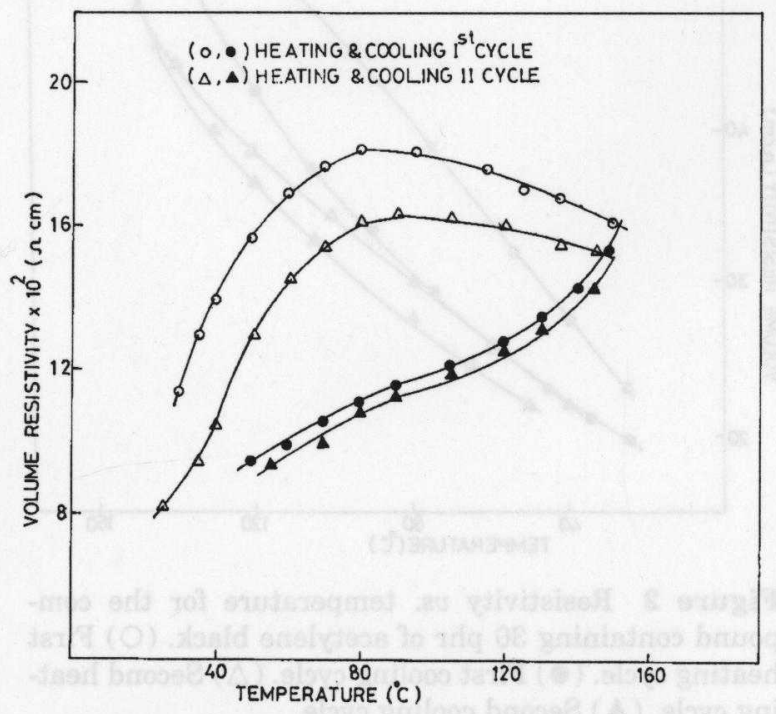

Figure 6 Resistivity $v s$. temperature for the compound containing $30 \mathrm{phr}$ of ISAF black. (O) First heating cycle. $(\bullet)$ First cooling cycle. $(\triangle)$ Second heating cycle. ( $\Delta$ ) Second cooling cycle.

wherein the increase in free volume holes becomes appreciable. Similar to this, the changes in conductivity during the heating cycle for the compounds containing ISAF black may be due to the breakage of the clusters of ISAF black below $80^{\circ} \mathrm{C}$ and reformation again above $80^{\circ} \mathrm{C}$. On cooling,

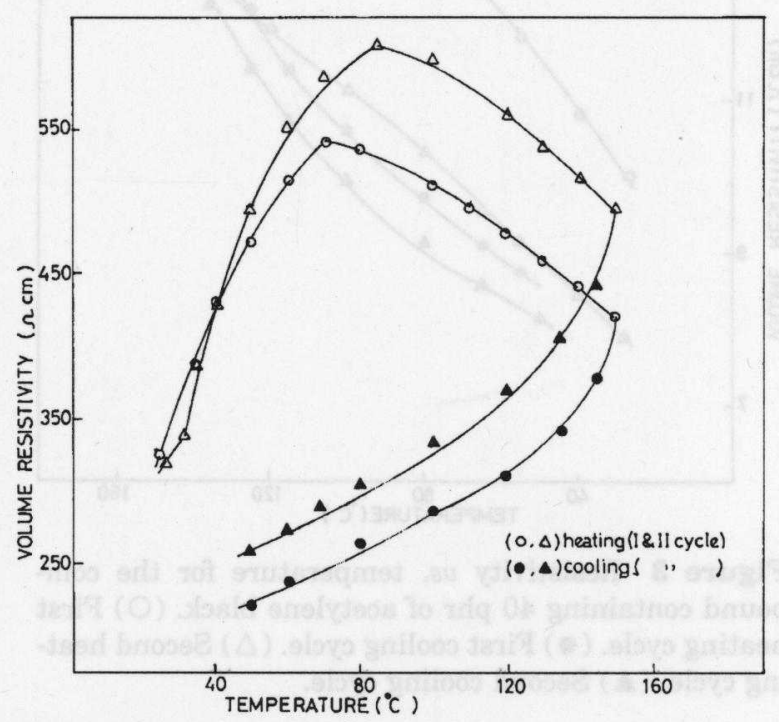

Figure 7 Resistivity $v s$. temperature for the compound containing $40 \mathrm{phr}$ of ISAF black. (O) First heating cycle. ( ) First cooling cycle. $(\triangle)$ Second heating cycle. ( $\mathbf{\Lambda})$ Second cooling cycle. 


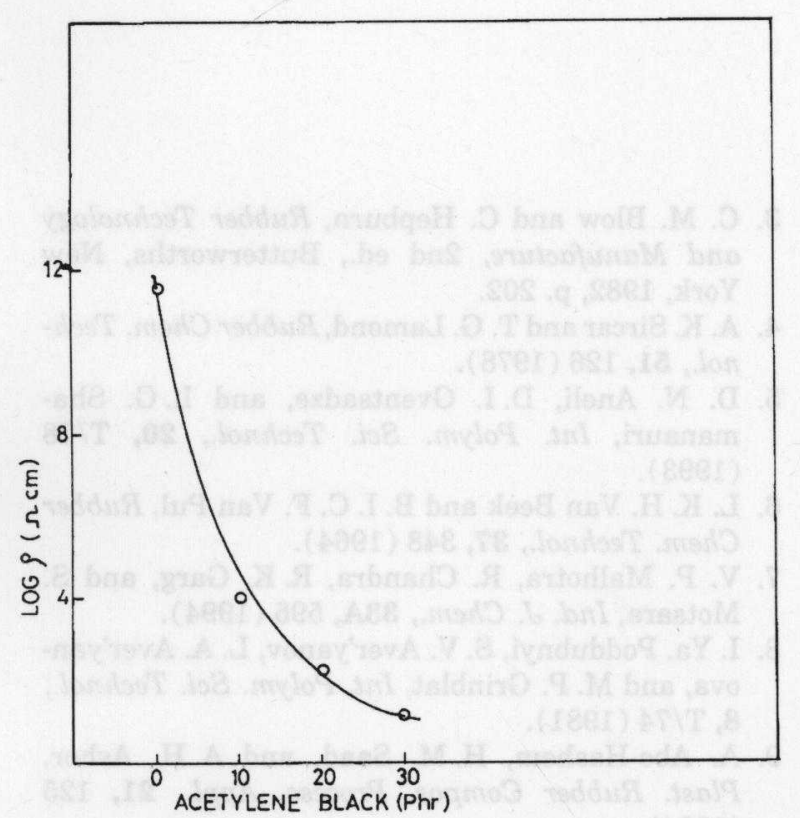

Figure $8 \log \rho v s$. amount of acetylene black for the compounds containing $25 \mathrm{phr}$ of copper powder and 10 phr of graphite powder.

only the reformation of ISAF black aggregates takes place and there is no increase in the resistivity versus temperature cooling curve, thus showing that the conductivity increases on cooling.

The addition of copper powder and graphite powder into silicone rubber has only very little effect on the resistivity as shown in Figure 8. As the amount of acetylene black increased, resistivity decreased. The temperature dependence of resistivity of these composites are also noted. Figures 9 and 10 show the temperature dependence of resistivity for compounds containing 20 and 30 phr of acetylene black, along with $25 \mathrm{phr}$ of copper powder and $10 \mathrm{phr}$ of graphite powder. The nature of the curve is similar to that of composites containing acetylene black alone.

\section{CONCLUSIONS}

The following conclusions can be drawn from this investigation.

1. The resistivity of the composites that contain carbon blacks like acetylene black, lamp black, and ISAF black decreases as the carbon black concentration increases.

2. The mechanical properties like tensile

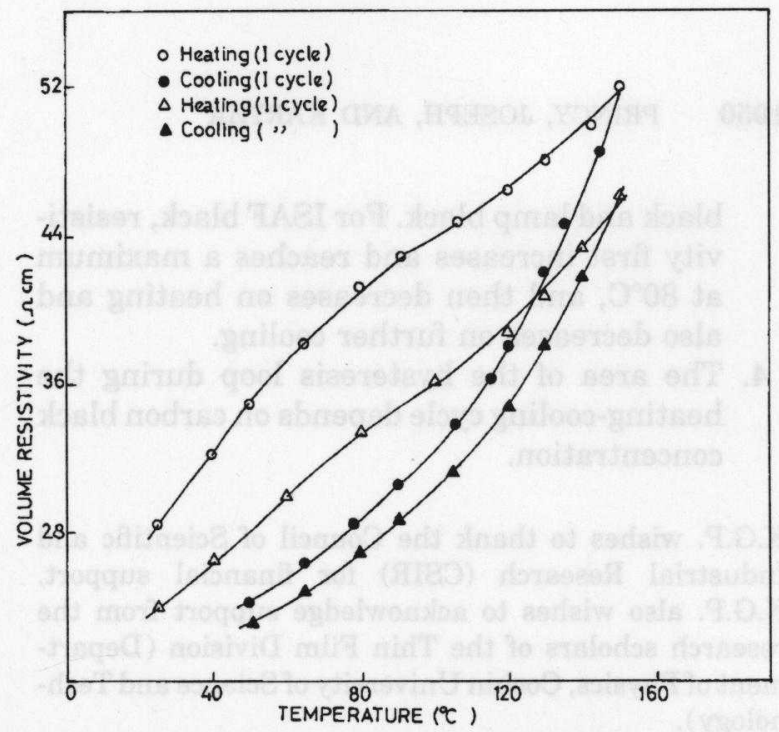

Figure 9 Resistivity $v s$. temperature for the compound containing $20 \mathrm{phr}$ of acetylene black, $25 \mathrm{phr}$ of copper powder, and $10 \mathrm{phr}$ of graphite powder. (O) First heating cycle. $(\bullet)$ First cooling cycle. $(\triangle)$ Second heating cycle. ( $\mathbf{\Delta})$ Second cooling cycle.

strength, tear strength, and elongation at break decreases, and hardness increases as the amount of carbon black increases.

3. Resistivity increases on heating and decreases on cooling in the case of acetylene

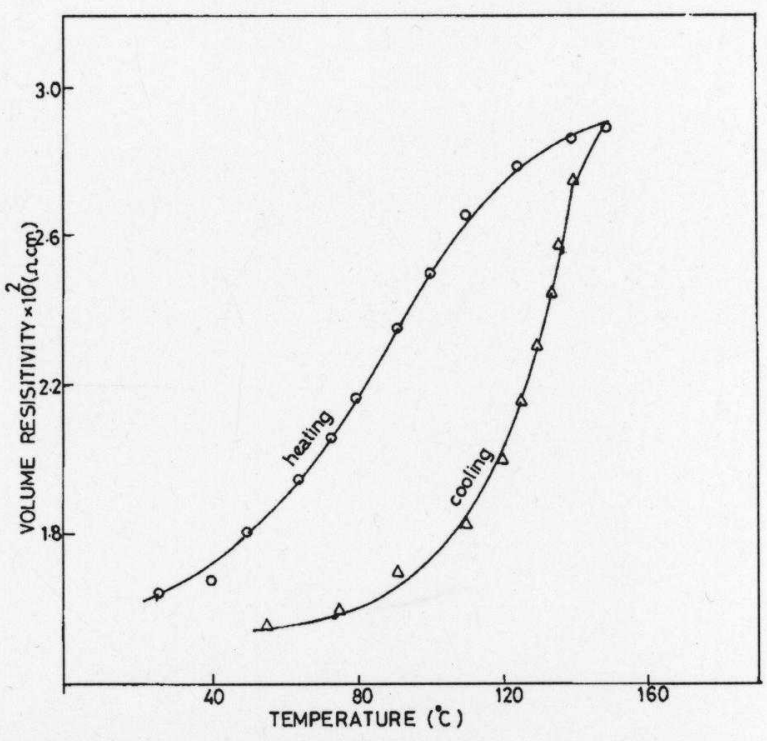

Figure 10 Resistivity $v$ s. temperature for the compound containing $30 \mathrm{phr}$ of acetylene black, $25 \mathrm{phr}$ of copper powder, and $10 \mathrm{phr}$ of graphite powder. (O) Heating cycle. $(\triangle)$ Cooling cycle. 
black and lamp black. For ISAF black, resistivity first increases and reaches a maximum at $80^{\circ} \mathrm{C}$, and then decreases on heating and also decreases on further cooling.

4. The area of the hysteresis loop during the heating-cooling cycle depends on carbon black concentration.

K.G.P. wishes to thank the Council of Scientific and Industrial Research (CSIR) for financial support. K.G.P. also wishes to acknowledge support from the research scholars of the Thin Film Division (Department of Physics, Cochin University of Science and Technology).

\section{REFERENCES}

1. A. I. Medalia, Rubber Chem. Technol., 59, 432 (1986).

2. M. H. Polley and B. B. Boonstra, Rubber Chem. Technol., 30, 170 (1957).
3. C. M. Blow and C. Hepburn, Rubber Technology and Manufacture, 2nd ed., Butterworths, New York, 1982, p. 202.

4. A. K. Sircar and T. G. Lamond, Rubber Chem. Technol., 51, 126 (1978).

5. D. N. Aneli, D. I. Gventsadze, and L. G. Shamanauri, Int. Polym. Sci. Technol., 20, T/78 (1993).

6. L. K. H. Van Beek and B. I. C. F. Van Pul, Rubber Chem. Technol., 37, 348 (1964).

7. V. P. Malhotra, R. Chandra, R. K. Garg, and S. Motsara, Ind. J. Chem., 33A, 595 (1994).

8. I. Ya. Poddubnyi, S. V. Aver'yanov, L. A. Aver'yanova, and M. P. Grinblat, Int. Polym. Sci. Technol., 8, T/74 (1981).

9. A. Abo-Hashem, H. M. Saad, and A. H. Ashor, Plast. Rubber Compos. Process. Appl., 21, 125 (1994).

10. P. B. Jana, Plast. Rubber Compos. Process. Appl., 20, 107 (1993).

11. S. Miyauchi, Int. Polym. Sci. Technol., 12, T/49 (1985).

12. S. K. Bhattacharya and A. C. D. Chaklader, Polym. Plast. Technol. Eng., 19, 21 (1982). 